\title{
The Characteristic of Robusta Coffee Powder in Various Size Types and Coffee Weight in Sachets
}

\author{
Tri Agustina, Devi Silsia, and Lukman Hidayat \\ Agricultural Technology Department, Agiculture Faculty, University of Bengkulu \\ Jalan W.R. Supratman, Kandang Limun, Bengkulu, 38371a \\ Corresponding Author: lukman_hidayat@unib.ac.id
}

\begin{abstract}
This Research aims to determine the performance influence of sachets on various sizes of bags and weight of coffee to the characteristics of the brew of coffee bags. The study uses complete random design with 2 treatment factors, the first factor of the volume of contents in the bag and the second factor of the packaging bag size. Analysed With ANOVA dan when the effect is noticeable. It will be followed by using a DMRT on 5\%. significant levels. The research at moisture content and ash content is suitable for the raw material of coffee bags. Coffee Sari qualified SNI is on the treatment of the volume of $1 / 4$ content and small bag size with a yield of $22.02 \%$ coffee juice. The results of the analysis on the missing coffee weight test were obtained the highest value found in the volume of the $1 / 3$ content with a large bag size resulted in 2.73 grams of lost coffee weight. The lowest value is on the $1 / 2$ content volume and the medium size is 0.17 grams. The sensory test was derived that the panelists preferred it to the size of a large bag and the appropriate volume of contents to fill the bag with a volume of $1 / 3$.
\end{abstract}

Keywords : Coffee characteristic, bag size and coffee weight

Reference to this paper should be made as follows :

Agustina, T., D. Silsia, and L. Hidayat. 2020. The Characteristic of Robusta Powder Coffe in Various Size Types and Coffe Weight on Sachets. Agritropica: Journal of Agricultural Science. 3(2): 58-69. Doi: https://doi.org/10.31186/Jagritropica.3.2.58-69

\section{INTRODUCTION}

Coffee is a beverage ingredient that has been known throughout the world. Forms of processed coffee available on the market are various, one of which is ground coffee. Coffee powder after brewing, will give results that are unique in terms of color, aroma, flavor, solubility and purity. Coffee drinks are popular with the wider community because of the distinctive flavors that are caused during brewing. Coffee flavor and refreshing effect caused by the constituent components of coffee, including caffeine. The constituent components will dissolve when the ground coffee is brewed with boiling water. The solubility of the coffee component is influenced by the size of the powder and the temperature of the solvent (Achadiyah, 2007).
In the coffee brewing process, the level of smoothness becomes a factor that needs to be justified in order to obtain optimal brewing results. The smaller the size of the coffee grounds, the more extracted coffee will be, but the process will produce a bitter and bitter taste. Granules ground coffee has a large surface area so that the compounds forming aroma and taste dissolve easily in hot water.

In addition to particle size, the brewing temperature is also an important factor that will affect the taste of the coffee dish. The Specialty Coffee Association of America (SCAA) states that the water temperature used for brewing coffee is $92^{\circ} \mathrm{C}$, the minimum technical requirements for drink recipients or consumers is not less than 
$80 \mathrm{oC}$, and no more than 85oC. Meanwhile, the ideal temperature for serving coffee is at $62.8-68.3^{\circ} \mathrm{C}$ (Asiah, 2017).

So far, the method of brewing coffee is considered impractical, because it provides sediment (pulp), so people turn to instant coffee (Achadiyah, 2007). Ground coffee that must be added with sugar and brewed with hot water has been replaced by instant coffee which is packed in sachets. This will help people who are very busy and who need everything practical (Siswanto et al., 2011). The disadvantage of making instant coffee is that there is a recrystallization process with a long heating process and with high temperatures. The heating process can cause sucrose to degrade into fructose and glucose. This can cause the value of Brix degree of instant coffee roomie to be lower (Nurhayati, 2017).

Alternatives to facilitate the presentation of ground coffee can be sought by preparing packaged ground coffee as in the presentation of tea bags (Achadiyah, 2007). Dip coffee is obtained from crushed coffee beans and then put into a package that is shaped like a filter (filter). With the existence of dyed coffee, the pulp that is usually produced when the coffee is brewed with hot water will be reduced or even none at all (Nurhayati, 2017).

At this stage the importance of the type of packaging, because if the packaging is too thin as commonly used for teabags, it will be easily released, considering the weight of coffee when wet is greater than the weight of wet tea. Likewise, if the size of the packaging pores is too large, a lot of coffee will dissolve, considering the size of the coffee grains are very fine. That is why dyed coffee requires packaging paper which has a higher thickness and denser pore size (Sugiantoro et al., 2015).

The development of coffee products in the form of coffee bags has not been developed yet (Nurhayati, 2017). However, currently available dip bags on the market with various types of sizes. But it is not yet known the volume to fill the bag and the size of the pores to produce the best dip coffee. Based on this description, it is what makes researchers interested in researching it. So that later it can be seen the volume and pores that are suitable for making the best and preferred teabags by the public.

\section{RESEARCH METHODS}

\section{Place and time}

This research was conducted at the University of Bengkulu Agricultural Technology Laboratory starting on May 7-July 19, 2019.

\section{Tools and materials}

The tools used are dip bags, flasks, stopwatches, mesh mesh size of 35 mesh, erlenmeyer, measuring flask, boiled flask, filter paper, goblet, oven, desiccator, hot plate and analytical scale, porcelain cup. The ingredients used are robusta ground coffee which is available in the market, hot water, and distilled water. The material used for the analysis of physical quality and sensory of coffee is a questionnaire.

\section{Research design}

The experimental design used was a completely randomized design with 2 factors. The first factor is the volume of contents showing the weight of coffee in the bag and the second factor is the size of the coffee bag. Each repetition of 3 times. For the volume of the contents of the bag is divided into 3, 
namely the volume $1 / 4$ (A1), $1 / 3$ (A2), and $1 / 2$ (A3). As for the size of coffee bags, there are three, namely: coffee bags with small size B1 $(5.50 \mathrm{~cm} \times 7.00 \mathrm{~cm})$, coffee bags with medium size B2 (7.50 $\mathrm{cm} \times 6.25 \mathrm{~cm}$ ), and bags coffee cup with B3 size $(7.00 \mathrm{~cm} \times 9.00 \mathrm{~cm})$. The following is the weight of ground coffee used:

$$
\left.\left.\left.\begin{array}{l}
\mathrm{B} 1=1,83 \text { gram } \\
\mathrm{B} 2=3,33 \text { gram } \\
\mathrm{B} 3=6,11 \text { gram }
\end{array}\right\} \mathrm{A} 1(1 / 4) \quad \begin{array}{l}
\mathrm{B} 1=3,15 \text { gram } \\
\mathrm{B} 2=4,52 \text { gram }
\end{array}\right\} \mathrm{A} 2(1 / 3) \quad \begin{array}{l}
\mathrm{B} 1=5,41 \text { gram } \\
\mathrm{B} 2=7,10 \text { gram } \\
\mathrm{B} 3=13,36 \text { gram }
\end{array}\right\} \mathrm{A} 3(1 / 2)
$$

\section{Data analysis}

Data obtained from observations will be analyzed by ANAVA to get the treatment effect. And if there are real differences, it will be continued with the DMRT test (duncan multiple range test) at a significant level of $5 \%$ using the SPSS 23 program.

\section{RESULTS AND DISCUSSION}

\section{Characteristics of Raw Materials}

Testing includes water content (physical quality) and ash content (chemical quality). In this observation, the observations were compared with SNI for dipped coffee (SNI 01-42821996). The results of physical and chemical quality testing of ground coffee used as raw material can be seen in table 1.

The results of the ground coffee test, which can be seen in Table 5, show water content $<7 \%$ and ash content $<5 \%$ so that it meets the specifications of the SNI 01-4282-1996 quality requirements for dyed coffee (BSN, 1996). Because the water content and ash content meet SNI, so this ground coffee is suitable when used as a raw material for making coffee bags.

The water content of a product needs to be known because water can affect the appearance, texture and taste of the material. In addition, the water content in food ingredients also determines acceptability, freshness, and endurance (Nopitasari, 2010). However, high water content in dry products such as coffee grounds decreases its shelf life (Tejasari, 2010). High water content makes it easy for bacteria, mold, and yeast to multiply, so there will be changes in food (Herman, 2011). Penyangraian aims to reduce water content, cause discoloration, and form specific aromas (Fajriana, 2018).

\section{Packaging Characteristics (Coffee Bags)}

Dye bags that have been purchased at the store are measured in pore size using a stereo microscope that has been connected to a computer. The measurement is done because there is no information about the pores of the bag. Measurement of pores in a coffee bag can be seen in Figure 2.

Table 1. Comparison of water content and ash content in ground coffee with SNI 01-4282-1996.

\begin{tabular}{cccc}
\hline \multirow{2}{*}{ Observation Variable } & \multirow{2}{*}{ Treatment } & \multicolumn{2}{c}{ SNI 01-4282-1996 } \\
\cline { 3 - 4 } & & Requirements 1 & Requirements 2 \\
\hline Moisture content $(\% \mathrm{w} / \mathrm{w})$ & 5,76 & Max 7 & Max 7 \\
\hline Ash content $(\% \mathrm{w} / \mathrm{w})$ & 4 & Max 5 & Max 5 \\
\hline
\end{tabular}




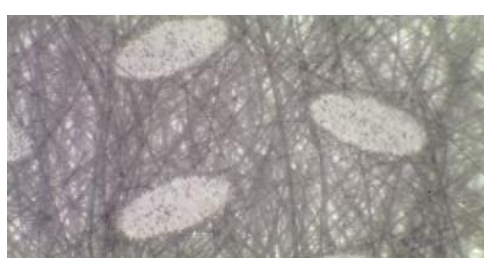

Small bag

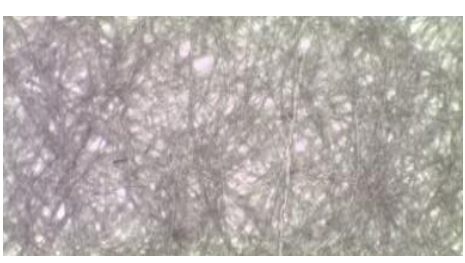

Medium bag

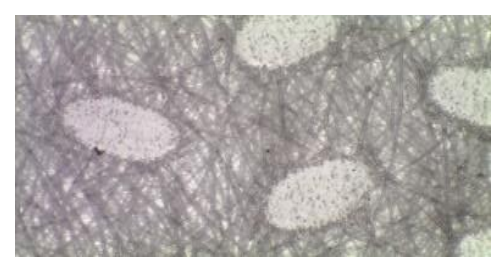

Large bag

Figure 2. Results of porous coffee bag measurement by stereo microscope

The test results obtained by using a $35 \times$ magnification is the small size of the bag obtained $0.852 \mathrm{~mm}$ and the width is $0.454 \mathrm{~mm}$. in medium size bags, $0.102 \mathrm{~mm}, 0.0886 \mathrm{~mm}$ and 0.103 $\mathrm{mm}$ were obtained. Whereas in the big bag, the length value is $0.856 \mathrm{~mm}$ and the width is $0.521 \mathrm{~mm}$. Each bag size has different pores and this will influence the final result of the coffee bag itself.

\section{Coffee Juice}

The content of ground coffee extract shows the amount of substances dissolved in water during brewing (Nopitasari, 2010). The results of testing ground coffee extracts produced from each treatment in this study are presented in Table 7 and Figure 3.

Based on SNI 01-4282-1996, the quality requirements for dipped coffee for coffee extraction parameters are 20$36 \%$ for the quality of ground coffee I and a maximum of $60 \%$ for the quality of ground coffee II. The results of the testing of the content of the dyed coffee extract obtained from each treatment were only one that could meet the standards set by SNI, namely in the treatment with a volume volume of $1 / 4$ and a medium bag size with a result of $22.02 \%$. While the lowest value is found in the treatment with the volume volume of $1 / 2$ and the size of large bags that produce $4.99 \%$.

Table 6. Comparison of coffee juice quality in dyed coffee with SNI 01-4282-1996.

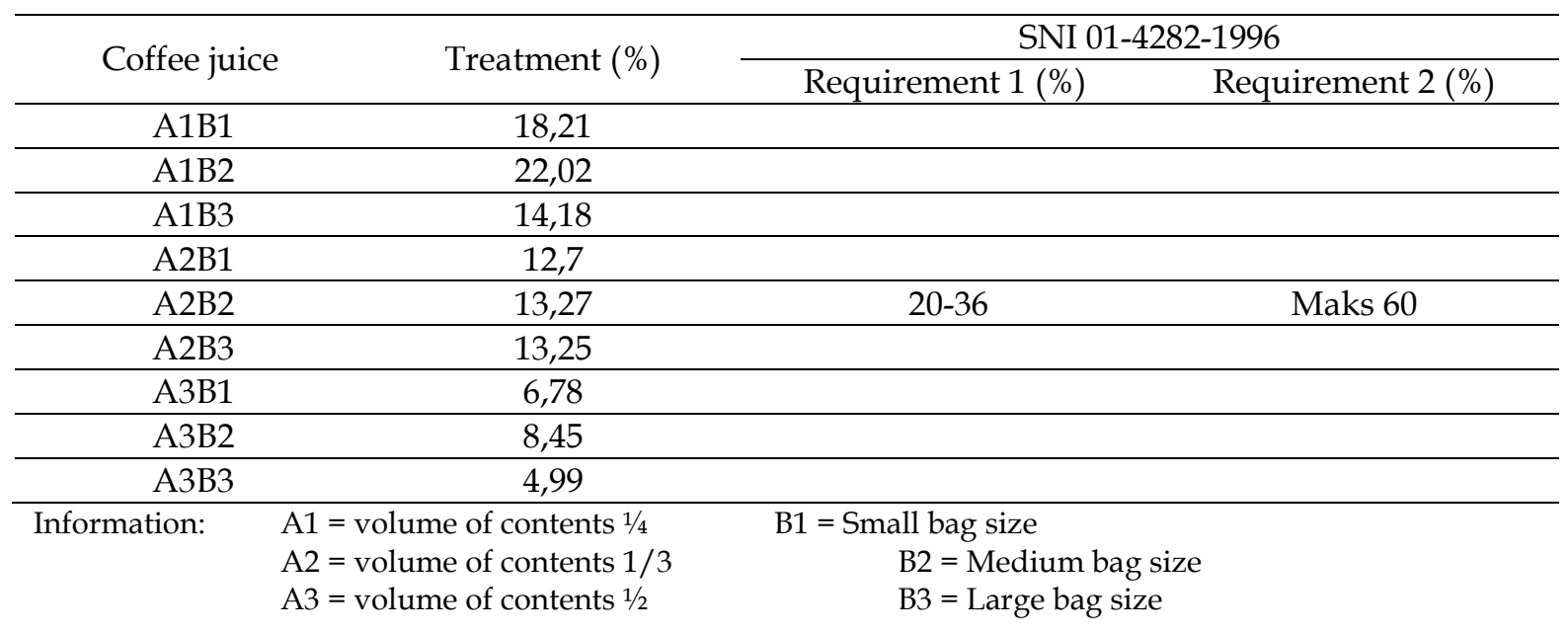




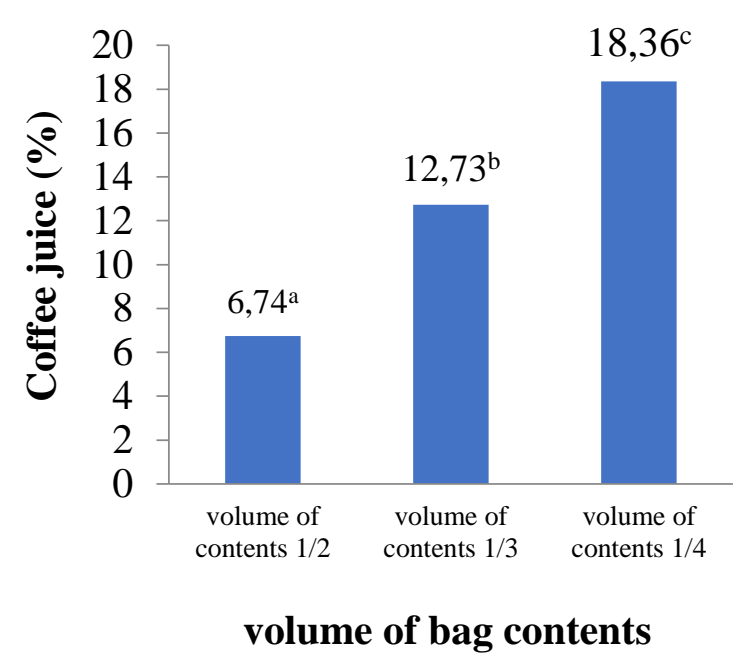

Note: numbers followed by different letters have a real effect

Figure 3. Graphs of dipped coffee juice content at various bag volumes

Analysis of Variance (ANOVA) results show that the treatment of the volume of the contents of the bag has a significant effect on the content of the dyed coffee extract. This can be seen from the ANOVA results that show a significant value $(\mathrm{P}<0.05)$, and have no significant effect on the treatment of the bags of coffee bags and for their interactions.

The value of coffee juice has a significant effect due to the volume of contents $1 / 4$ the amount is small so it makes it easy for the juice to dissolve when brewed using hot water.
Inversely if the volume is greater then the soluble juice is also less, it is due to the difficulty of the juice that comes out of the coffee bag because the coffee bags are more numerous and dense so that the coffee juice will dissolve more difficult. When viewed from the volume of contents and the size of coffee bags the highest percentage contained in the coffee juice is to use volume contents $1 / 4$ and by using medium size bags.

\section{The Weight of the Lost Coffee}

The weight that is lost is the weight that is not found in the bagged coffee grounds after brewing. The results of testing the lost coffee weights, resulting from each treatment in this study are presented in Figure 4.

The results of the analysis on the lost coffee weight test obtained the highest value found in the volume volume of $1 / 3$ and with the size of a large bag produces a lost coffee weight that is equal to 2.73 grams. The lowest value is found in the volume volume of $1 / 2$ and the size of the small bag size to produce 0.17 grams of coffee weight lost. The results of steeping coffee can be seen in Figure 5.

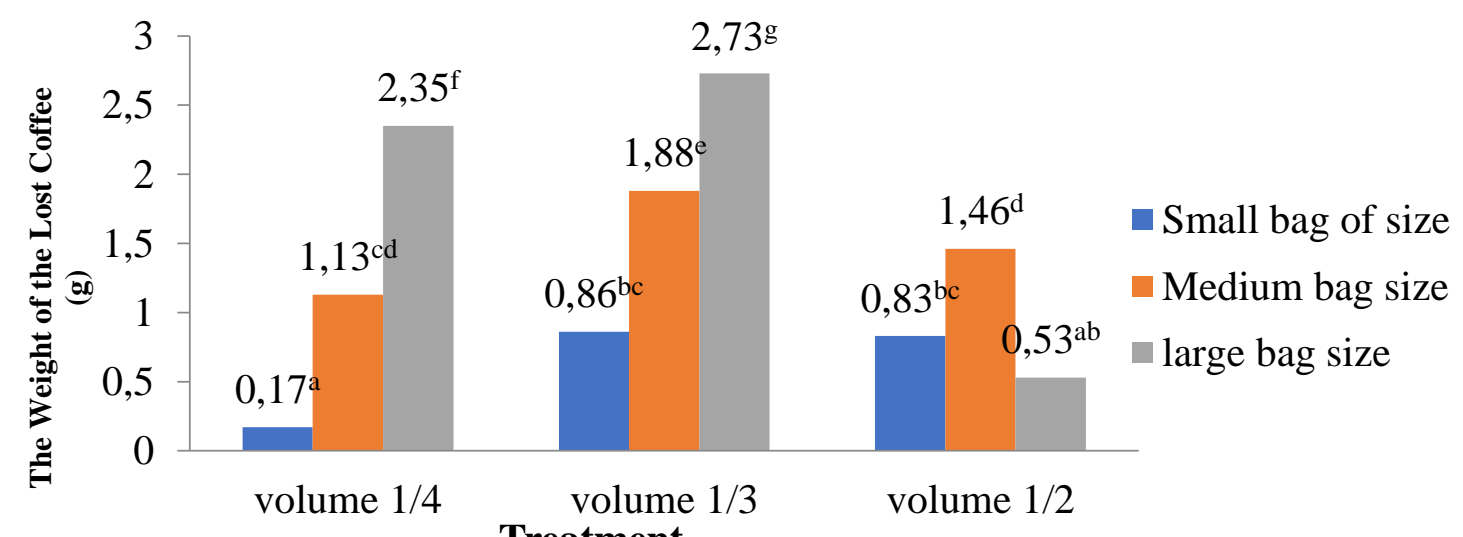

Note: numbers followed by the same letters have no significant effect $(\mathrm{P}>0.05)$

Figure 4. Graph of weight lost for each treatment 


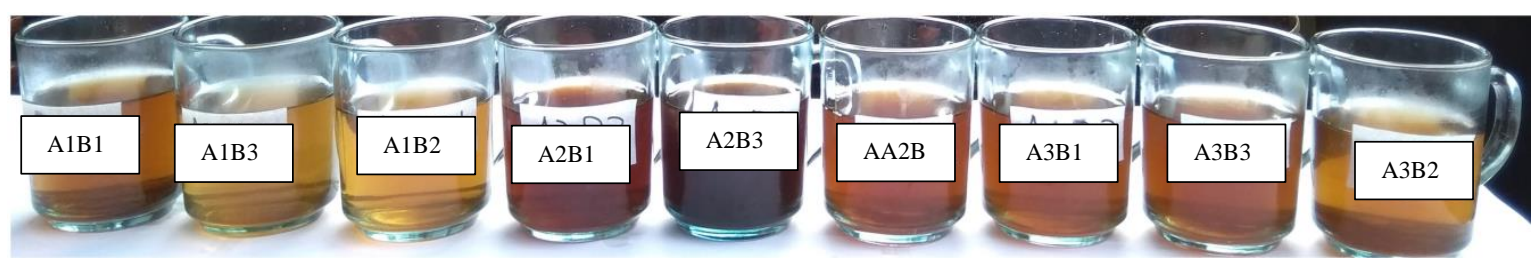

Figure 5. The results of coffee brewed for each treatment

Analysis of Variance (ANOVA) results of the treatment of the contents of the bag have a significant effect on the lost weight. This can be seen from the ANOVA results that show a significant value $(\mathrm{P}<0.05)$, and have a significant effect on the treatment of the bags of coffee bags and for their interactions. The results of DMRT follow-up tests at the $5 \%$ level showed that the volume of bag contents $1 / 2$ significantly affected the volume of bag contents $1 / 3$ and $1 / 4$.

When viewed from the treatment of the contents of this $1 / 3$ bag that greatly affects the lost weight is the amount of ground coffee contained in the coffee bag. Because more and more contents are in the bag, it will make it harder for the coffee powder to come out of the bag. If less and less ground coffee is in the bag, less coffee will come out. Different if ground coffee with medium size or $1 / 3$ because it is not too dense that is in the bag making it easier for the ground coffee to come out of the bag of coffee bags. But the presence of ground coffee that comes out of the bag coffee does not mean the quality of the coffee is reduced, because the main function of this bag is to reduce the deposits found in ground coffee when it is brewed and if possible can even eliminate the deposits contained in the coffee while being brewed. And this is in accordance with research from Nurhayati (2017), which states that in the presence of dipped coffee, the pulp that is usually produced when coffee is brewed with hot water will be reduced or even nonexistent. Judging from the size of the bag, it can affect the ground coffee that comes out due to the more volume of coffee content contained in the bag. The lowest value is found in the size of the small bag, due to the smaller size of the bag. So that the ground coffee that comes out is less because the volume of contents contained in the bag is less when compared to the volume of the other bag.

When viewed from the volume of bag contents and bag size, that the best treatment to get the best coffee bag is to use a volume of coffee $1 / 3$ of the size of the bag and by using a large bag size. Because when associated with the level of consumer preferences for the color of the brewed coffee itself. Where the more coffee that dissolves when brewed, the color is more intense (black) and it is increasingly in demand by panelists, it can be seen in Figure 4 .

\section{Color}

Color is a very important component to determine the quality or degree of acceptance of a food or food product. Even though a food is considered good and has a very good texture, it has a color that is less pleasing to the eye or gives the appearance of deviating from the color it should be, so it is not suitable for consumption (Angelia, 2018). The results of the color sensory testing produced from each treatment in this study are presented in Figure 6. 


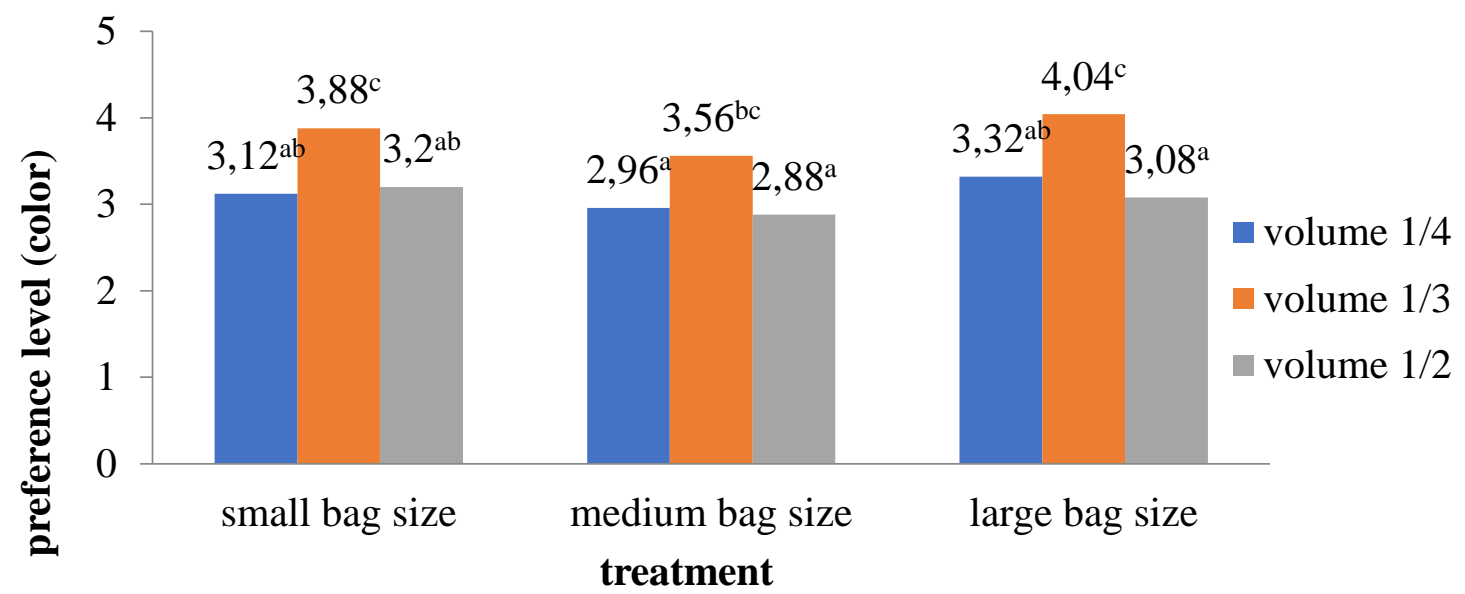

Note: numbers followed by the same letters have no significant effect $(\mathrm{P}>0.05)$

Figure 6. Graph of preference level (color) for each treatment

Analysis of Variance (ANOVA) the volume of contents. Where is results show that the two treatments ground coffee that can dissolve when have a significant effect. This can be the brewing process is more when seen from the ANOVA results that compared with coffee bags with smaller show a significant value $(\mathrm{P}<0.05)$. The bag sizes and fewer bag volumes. So test results on the test of liking (color) that it can produce coffee bags that are of brewed coffee drink water (do not darker or more concentrated.

like it until very like) found that in both treatments obtained the highest value in the volume volume of $1 / 3$ and the size of large bags with an average value of 4,04 . And the lowest average value is in the volume of $1 / 2$ bag contents and medium bag sizes with an average of 2.88 .

This color is influenced by the size of the bag contained in the bag and

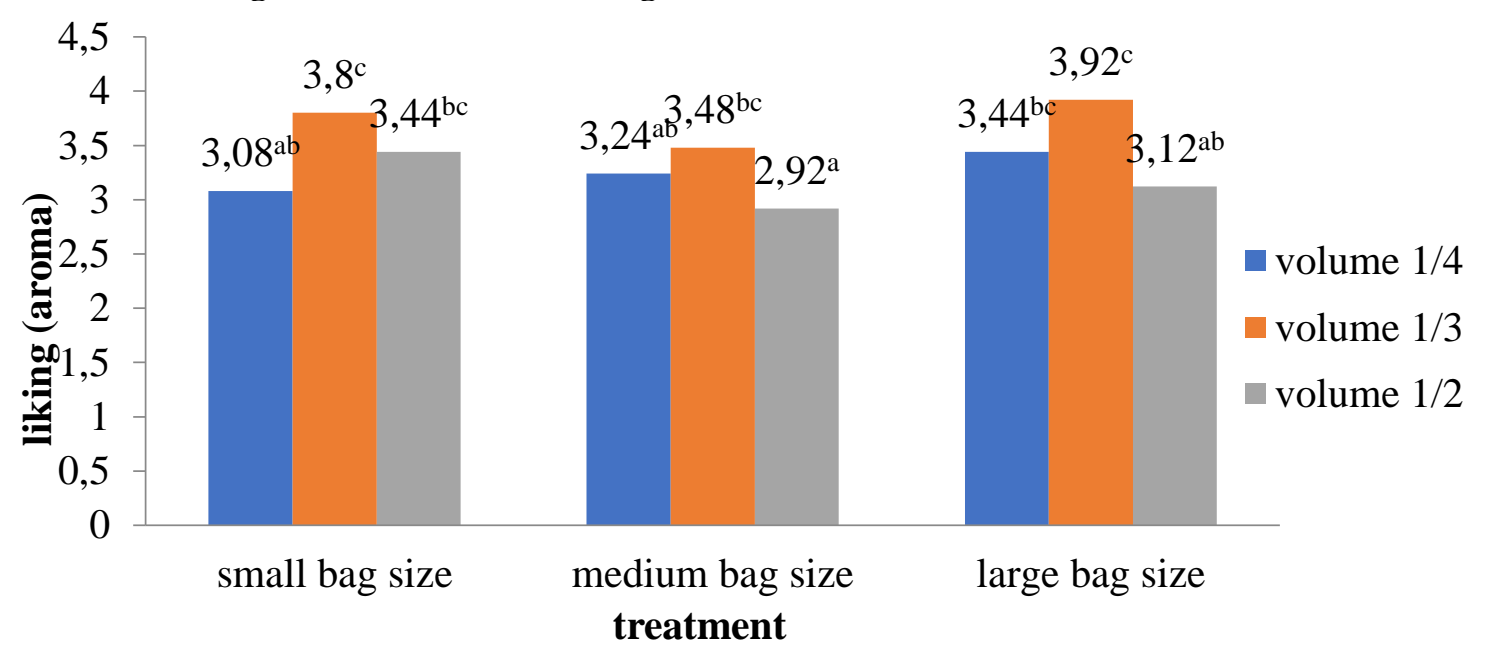

Note: numbers followed by the same letters have no significant effect $(P>0.05)$

Figure 7. Graph of preference (aroma) of coffee brewed results for each treatment 
Analysis of Variance (ANOVA) results show that the two treatments have a significant effect. This can be seen from the ANOVA results that show a significant value $(\mathrm{P}<0.05)$. The test results on the test level of liking (aroma) of brewed coffee drink water (do not like to very like). It was found that in both treatments the highest value was obtained in volume $1 / 3$ and large bag sizes with an average value of 3.92. And the lowest average value is in the volume of $1 / 2$ and medium bags with an average of 2.92. This shows that the aroma of steeping coffee with A2B3 treatment is stronger when compared to coffee with other treatments. That is because the size of the bag in this treatment is larger and because the volume of the contents of the bag is $1 / 3$ easier to dissolve because the volume of contents in the bag is not too dense so that it makes it easier for the coffee powder to dissolve during the brewing process. This is in accordance with research from Nurhayati (2017), the more volatile compounds that dissolve in water when brewing the sharper the resulting aroma.
Taste

Taste is one of the main factors that determine the level of consumer acceptance of a food product. Consumer taste is also a determining factor in whether or not the taste of food products is accepted (Nurhayati, 2017). The sensory quality of coffee brewed taste is presented in Figure 8.

Analysis of Variance (ANOVA) results show that the two treatments have a significant effect. This can be seen from the ANOVA results that show a significant value $(\mathrm{P}<0.05)$. The test results on the test level of liking (taste) of brewed coffee drink water (do not like to very like). It was found that in both treatments the highest value was obtained in volume $1 / 3$ and large bag sizes with an average value of 3.92 . The lowest average value is in the volume of $1 / 2$ bag contents and medium bag sizes with an average of 2.88 . This shows that the taste of brewed coffee with A2B3 treatment is more bitter and is preferred by panelists when compared to coffee dipped with other treatments. That's because the size of the bag in this treatment is bigger and because the volume

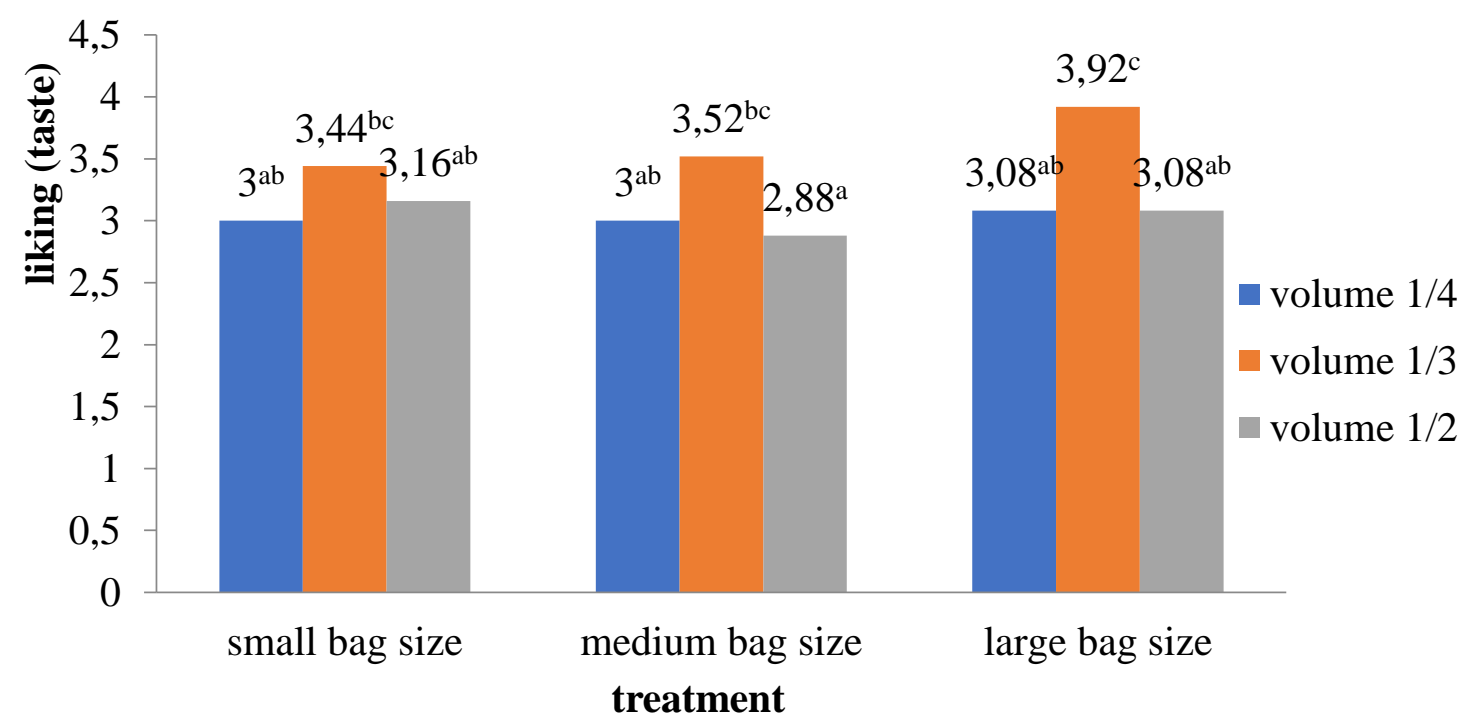

Note: numbers followed by the same letters have no significant effect $(\mathrm{P}>0.05)$

Figure 8. Graph of the level of preference (taste) of coffee brewed for each treatment 
of the contents of the bag is $1 / 3$ easier to dissolve because the volume of the contents in the bag is not too dense so that it makes it easier for the coffee powder to dissolve during the brewing process. Caffeine compounds, aliphatic acid, khologenat acid, and trigonelin play a role in the formation of a distinctive main coffee flavor, namely bitter. Bitter taste that causes less sensation of coffee taste that is not right. Caffeine has no direct effect on taste, but in some types of coffee, caffeine is associated with other components such as fat and chlorogenic acid so that it determines the bitterness of coffee (Tejasari, 2010).

Through sensory testing that has been carried out using a questionnaire, it was found that the size of the bag and volume of contents most liked by the panelists through the test of the level of color, aroma and taste that has been filled by the panelists namely with the size of a large bag and the volume of contents suitable for filling the bags i.e. with a volume of $1 / 3$.

\section{CONCLUSION}

The characteristics of coffee extracts, while the size of the bags and their interactions have no significant effect. Volume of bag contents (coffee weight) and bag size and interactions on the characteristics of lost coffee weights have a significant effect on the performance of bags of coffee bags. Organoleptic test (color, aroma, and taste) have a significant effect on the performance of a bag of coffee bags and the best value is the treatment of the volume of contents of a bag 1/3 and the size of a large bag with criteria value of 4.

\section{REFERENCES}

Achadiyah, S. 2007. Study of Making Ginger Coffee (Study of Ginger
Coffee Bag Preparation). Agroteknose. 3 (2): 1-6.

Angelia, I. O. 2018. Test Characteristics of Non-Caffeine Coffee from Papaya Seeds with Variation of Irradiation Length (Characteristics Test of Non Caffeine Coffee With Variation of Papaya Seeds While Irradiation). Journal of Agritech Science. 2 (1): 16-29.

Annishia, F. B and M. S. Setiawan. 2018. The Effect of Coffee Product Quality on Consumer Satisfaction at Jade Lounge Swissbel Residences Kalibata Jakarta. Journal of Hospitality and Tourism.4 (1): 1-69.

Ardianti, A. D and K. Fibrianto. 2017. Literature Review: Alkaline Water and Oxygenated Water as Coffee Brewers. Journal of Food and Agro-Industry. 5 (3): 1-5.

Arwangga, A. F, I. A. R. A. Asih and I. W. Sudiarta. 2016. Analysis of Caffeine Content in Coffee in Sesaot Narmada Village Using Uv-Vis Spectrophotometry. Journal of Chemistry. 10 (1): 110-114.

Asiah, N, F. Septiyana, U. Saptono, L. Cempaka and D. A. Sari. 2017. Identification of Robusta Cibulao Coffee Body Dish Taste at Various Temperatures and Smoothness of Brewing. Barommeter. 2 (2): 52-56.

BSNI. 1992. Instant Coffee. SNI 01-29831992.

BSNI. 1996. Dipping Coffee. SNI 014282-1996.

BSNI. 2004. Coffee Powder. SNI 013542-2004. 
BSNI. 2006. Organoleptic and or Sensory Testing Instructions. SNI 01-2346-2006.

Edvan, B. T, R. Edison and M. Same. 2016. Effect of roasting type and duration on Robusta (Coffea Robusta) Coffee Quality. Aip Journal. 4 (1): 3140.

Erdiansyah, N. P, and Yusianto. 2012. Relationship of Light Intensity in Gardens with Taste and Profile Profile of Caffeine in Several Robusta Coffee Clones. Pelita Perkebunan. 28 (1): 14-22.

Fajriana, N. H and I. Fajriana. 2018. Analysis of Caffeine Levels of Arabica Coffee (Coffea arabica L.) on Roasted Temperature Variations in Ultra-Violet Spectrophotometry. Analytes. 3 (2): 148-162.

Herman, R. Rusli, E. Ilimu, R. Hamid and Haeruddin. 2011. Analysis of Mineral Content in Nipa Fruit Ash (Nypa fructicans) Kaliwanggu, Kendari Bay, Southeast Sulawesi. J. Trop. Pharm. Chem. 1 (2): 107-113.

Hutasoit, L. 2018. Quality Control of Coffee Receipt Production Through the Taste Test Process at PT.Volkopi Indonesia by Using Statistical Quality Control. Final Project Reports D-3 Study Program Statistics Faculty of Mathematics and Natural Sciences, University of North Sumatra. Field.

Kristiyanto, D, B. D. H. Pranoto and Abdullah. 2013. Decreasing Arabica Coffee Caffeine Levels With Fermentation Process Using Nzkor Mz-15. Journal of
Chemical Technology and Industry. 2 (4): 170-176.

Lawless, H. T and Heyman. 1999. Sensory Evaluation of Food: Principle and Practices. Maryland USA: Aspen Publisher, Inc. Gaithersburg.

Muttalib, S. A., J. Nugroho and N. Bintoro. 2012. Identification of Blending Aroma of Arabica and Robusta Coffee with Electronic Nose Using a Pattern Recognition System. Proceedings of the Denpasar National Seminar on July 13-14, 154-163.

Nopitasari, I. 2010. The Process of Processing Coffee Powder (Mixture of Arabica and Robusta) And Their Quality Changes During Storage. Essay. Faculty of Agricultural Technology Bogor Agricultural University. Bogor.

Nurhayati, N. 2017. Sensory Characteristics of Dip and Instant Coffee Robusta and Arabica Varieties Sensory Characteristics of Coffee Bag and Instant Coffee of Robusta and Arabica Varieties. Journal of Scientific Innovation. 17 (2): 80-85.

Oktadina, F. D., B. D. Argo and M. B. Hermanto. 2013. Utilization of Pineapple (Ananas comosus L. Merr) for Decreasing Caffeine Levels and Improving Coffee Flavor (Coffea Sp) in Coffee Powder Manufacturing. Journal of Tropical Agricultural Engineering and Biosystems. 1 (3): 265-273. 
Pradipta, K, and K. Fibrianto. 2017. Journal Review of the Difference of Brewed Water on Coffee Multisensory Perception. Journal of Food and Agro-Industry. 5 (1): 85-91.

Purnamayanti, N. P. A, I. B. P. Gunadnya and G. Arda. 2017. Effect of Temperature and Length of roasting on Physical Characteristics and Sensory Quality of Arabica Coffee (Coffea arabica L). Journal of Beta (Biosystems and Agricultural Engineering). 5 (2): 39-48.

Ditjenbun. 2017. Agricultural Commodities Sub-Sector Coffee Plantation. Secretariat General of the Ministry of Agriculture. Jakarta.

Rahmawati, M. A and K. Fibrianto. 2018. Sensory Characterization of Robusta Dampit Coffee: Literature Review. Journal of Food and Agro-Industry. 6 (1): 75-79.

Reswita. 2016. Revenue and Value Added of Robusta Coffee Business in Lebong District (Case Study of the Rice Stamp Coffee Business). Agrisep. 15 (2): 255 - 261.

Sari, K and Yohana. 2015. Food Texture: A Part of Food Properties that is Forgotten in Maintaining the Function of Cognition. Makassar Dent J. 4 (6): 184-189.

Satyajaya, W, A. Rangga and F. Nurainy. 2014. Consumer Decision Making Process and Instant Coffee Product Attributes in Sachets. Journal of Industrial Technology and
Agricultural Products. 19 (2): 297-306.

Sembiring, T.P, A. P. Munir, Sumono and A. Rohananh. 2014. Roasting Temperature Test on Rotary Type Mechanical Coffee Roasters on Quality of Arabica Coffee (Coffea arabica). J. Food and Pert Engineering. 2 (1): 109113.

Siswanto, D, K. A. Damayanti and V. S. K. Dewi. 2011. Redesign of Instant Coffee Cup Packaging Based on User-Centered Design. Inasea. 12 (1): 22-32.

Sudiyarto, S. W and D.M. Krishna. 2012. Consumer Behavior Connoisseurs of Tubruk Coffee and Instant Coffee. Jsep. 6 (3): $1-11$.

Sudarmadji, S, B. Haryono and Suhardi. 1997. Analysis Procedures for Food and Agriculture Materials Fourth Edition. Liberty. Yogyakarta. 160 pg.

Sugiantoro, B, Y, B. Praharto and S. Dahlan. 2015. Appropriate Technology (Ttg) Sachet, Semi Automatic Coffee Machine for Increasing Production and Expansion of the Temanggungan Coffee Market Segment. ITEKS. 7 (2): 36-41.

Sugito, S. A. 2012. Cider Study as an Alternative to Coffee Product Diversification. Agritech. 32 (1): 98-104.

Suwarto and Y. Octavianty. 2010. Cultivation of Ungulan Plantation. Self-help Spreaders. Jakarta. 260 things.

Syah, H, Yusmanizar and O. Maulana. 2013. Physical Characteristics of Arabica Coffee Powder from 
Mechanical Milling with Addition of Corn and Sticky Rice. Indonesian Agricultural Technology and Technology Journal. 5 (1): 32-37.

Tejasari, Sulistyowati and R. A. A. Sari. 2010. Nutritional Quality and Level of Instant Decafosin Coffee Drinks. AGROTEK. 4 (1): 91-106.

Towaha, J, E. H. Purwanto and H. Supriadi. 2015. Quality Attributes of Arabica Coffee at Three Altitudes in Garut Regency. J. No: 2 (1): 29-34.
Winarno, F. G. 1993. Nutrition, Technology and Consumer Food. Gramedia Main Library. Jakarta. 416 p.

Yulisa, L, Y. Indriani and S. Situmorang. 2013. Consumption Behavior of University of Lampung Students towards Instant Coffee Powder (The Consumption Behavior of Instant Coffee Powder of the University Student of Lampung). JIIA. 1 (4): 326-333. 